\title{
Assessment of Tobacco-Related Oral Practices Among Young Adult Workers Involved in Building Construction of Noida Area, India-A Cross-Sectional Survey
}

\author{
Preeti Gupta ${ }^{1}$, Vivek Kumar Sharma ${ }^{2}$, Karnika Yadav ${ }^{3}$, Pramod Kumar Yadav ${ }^{4}$, \\ Prateek Jain ${ }^{5}$, Ravinder Singh ${ }^{6}$ \\ ${ }^{1}$ Senior Lecture Department of Oral Medicine and Radiology, I.T.S Dental college Muradnagar New \\ Delhi, India. \\ 2Professor Department of Periodontics and Community Dentistry, Dr. Z. A. Dental College AMU \\ Aligarh India. \\ 3Senior Lecture Department of Public Health and Community Dentistry, Nepal Medical College \\ Teaching Hospital, Kathmandu Nepal. \\ ${ }^{4}$ Assistant Professor, Department of Periodontics and Community Dentistry, Dr. Z. A. Dental College \\ AMU Aligarh India. \\ E-mail:pramod468@gmail.com \\ ${ }^{5}$ Senior Lecture Department of Public Health Dentistry, Maharana Pratap College of Dentistry \& \\ Research Centre, Gwalior, India. \\ ${ }^{6} \mathrm{MPH}$, Epidemiologist (IDSP/NVBDCP) Punjab, India.
}

$\underline{\text { Original Article }}$

\begin{abstract}
Oral health status of an individual is determined by multiple intrinsic and extrinsic factors. Dental health care seeking behaviour is an intrinsic factor that can influence the oral health status of an individual. A cross-sectional survey was conducted among young adult workers involved in building construction of Noida, India. A total of 340 subjects between 18-50 years of age were selected for the study. It contains the demographic profile, which includes age, gender, qualification, employment, residence, and oral adverse habits. Chi-square test and Fisher Exact test were used. When compared with literacy level and adverse oral habits results were significant as compare to residence address.
\end{abstract}

Keywords: Cross-sectional survey, Smoking, Tobacco, Laborers

\section{Introduction}

Oral habit refers to overindulgence in and dependence on various chemical substances mainly the use of tobacco \& alcohol leading to effects that are detrimental to the individual's physical and mental health. Smoking, chewing and consumption of alcoholic beverages have become common social habits in India.1Tobacco and alcohol use has been estimated to account for $50 \%$ of squamous cell carcinoma and that is about $30 \%$ of worldwide cancer burden. The prevalence of these habits was found to be more among men as compared to women. Also, the prevalence was higher among the rural population..2Tobacco products 
have been in existence for thousands of years among populations in South America and Southeast Asia. It was discovered by Christopher Columbus among the treasures of the New World. Spanish and Portuguese sailors carried tobacco to the other parts of the world and later it became popular in Europe. American Indians believed that tobacco possessed medicinal properties if used in the form of tobacco ointments, pastes, smoke, mouth rinses, etc to treat various maladies.3Tobacco use is a major global health problem and also leading preventable cause of premature death worldwide.4According to an Indian study at four urban centres, the prevalence of oral lichen planus varies between $0.02 \%-0.4 \% .5$ Tobacco smoking is one of the most important risk factors for oral mucosal lesions (OMLs), roughly half of periodontitis or inflammation around the teeth cases was attributed to current or former smoking. Smokeless tobacco causes gingival recession and white mucosal lesions. Tooth loss has been shown to be 2 to 3 times higher in smokers than in nonsmokers.6There was strong evidence that high alcohol intake is related to carcinogenesis especially cancer of oral cavity, pharynx, larynx, and liver. Alcohol beverage is causally related to cancers of the oral cavity and other parts of the human body. 5 Tobacco is used in both smoking and smokeless forms. Smoking habits include bidi, followed by cigarette, hookah, chillum, and chutta in this order. Other forms include hookli (clay pipe) and dhumti which are also smoked in a reverse way.7 Hence, the present study was conducted with an aim to assess the Tobacco-related oral habit among young Adult workers involved in Building construction of Noida area. These workers hail from rural and urban areas of the nearby region.

\section{Materials and Methods}

A cross-sectional survey was conducted among young adult workers involved in building construction of the Noida area from July 2013 to June 2014. Ethical approval was obtained from the 'Ethical Review Board' of I.T.S. Dental College Greater Noida.

A total of 340 subjects (male and female) aged between 18-50 years of age were selected for the study. It includes the demographic profile, which included age, gender, qualification, employment, residence, and oral adverse habits. Chi-square test and Fisher Exact test were used to find the significance of study parameters on a categorical scale between two or more groups. The data were analysed using the Statistical Package for Social Science (SPSS) 16 version.

\section{Results}

Table 1 Depicts 164(76.63\%) male and 116(92.06) females who were contractual workers. However $50(23.36 \%)$ males and $10(7.90 \%)$ females were from urban area as a laborer.

\begin{tabular}{|l|l|l|}
\hline Residence & Male & Female \\
\hline Urban & $164(76.63 \%)$ & $116(92.06 \%)$ \\
\hline Rural & $50(23.36 \%)$ & $10(7.93 \%)$ \\
\hline Total & 214 & 126 \\
\hline
\end{tabular}

Non- significant $\mathrm{p}$ value $=0.717$

Table1. Distribution of Study subjects based on their permanent residence 
Table 2 As far as the literacy level is concerned, 135(63.08\%) were male and 85(67.46\%) were female who contributed as a major group and was only educated up to primary standard. Only $35(16.35 \%)$ males and $18(14.28 \%)$ females had education up to the secondary level as minor contributions up to the secondary level.

\begin{tabular}{|l|l|l|}
\hline Literacy level & Male & Female \\
\hline Less than primary & $135(63.08 \%)$ & $85(67.46 \%)$ \\
\hline Less than secondary & $44(20.56 \%)$ & $23(18.25 \%)$ \\
\hline upto secondary & $35(16.35 \%)$ & $18(14.28 \%)$ \\
\hline Total & 214 & 126 \\
\hline
\end{tabular}

Significant $\mathrm{p}$ value $=0.000$

Table2. Distribution of Study subjects based on their on Literacy level

Table3. The distribution of male and female populations revealed oral habits in the form of smoking, Alcohol, smokeless and various types of habits associated with smoking and smokeless adoption. However only smoking contributed $36(16.82 \%)$ males and $19(15.07 \%)$ in females as one of the commonest oral habits. Smoking, smokeless and alcohol habits have been observed in only 14 (6.54\%) and 13(10.31\%) female workers.

\begin{tabular}{|l|l|l|}
\hline Habits & Male & Female \\
\hline Smoking & $36(16.82 \%)$ & $19(15.07 \%)$ \\
\hline Smokeless & $17(7.94 \%)$ & $31(24.60 \%)$ \\
\hline Alcohol & $21(9.81 \%)$ & $9(7.14 \%)$ \\
\hline Smoking +smokeless & $49(22.89 \%)$ & $22(17.46)$ \\
\hline Smoking+ Alcohol & $54(25.23 \%)$ & $14(11.11 \%)$ \\
\hline Smokeless+ Alcohol & $23(10.74 \%)$ & $18(14.28)$ \\
\hline Smokeless+ Alcohol+ Smoking & $14(6.54 \%)$ & $13(10.31 \%)$ \\
\hline Total & 214 & 126 \\
\hline
\end{tabular}

Significant $\mathrm{p}=0.000$

\section{Table3. Distribution of study subjects based on type of oral adverse habits}

\section{Discussion}

Table 1 Rural population contributes as a major laborer group due to low finical and less available in rural areas. Hence they were compiled to migrate for seeking livelihood thorough job and getting adopting these various types of habits following tiresome work. While comparing rural and urban populations involved in labour work was significant (chi-square 12.98, $\mathrm{p}$ value $=0.000$ for $\mathrm{d} . \mathrm{f}=1$.)

Table 2 reveals the literacy was low in 135(63.08) male and 85(67.46) female who adopted for various oral habits. This is a major contributory factor from a rural area where the jobs are rarely available for earning purpose and maintenance of the whole family (chi-square (0.607) with d.f $=2$ and p-value was 0.717.)

Table 3 among various oral habits found to be very significant while comparing the male and female. Whereas males had more prone to oral asocial habits as compared to females (chi-square 27.65, $\mathrm{p}$ value $=0.000$ ) which is highly significant. The results of our study are comparable to those obtained in the 
study performed in Hubuli, India (Arun et, 2011 Jabber et al., Rani et al., 2003; Saraswathi et al., 2006). In our studies smoking had also reported the same as more common in southern states of India however in one of the studies conducted at Chennai alcohol was the most common habit followed by the use of tobacco and areca nut. Many studies have shown a higher prevalence of areca nut chewing among younger individuals this may be due to a growing trend among the younger generation in the use of attractive packets of flavored areca products and attractive photographs which are widely marketed in India. The prevalence of oral habits was more among the population with a higher education group in our study. However, this was not true in many other previous studies with the increase in the prevalence of habits in the educated population the worst is yet to come.

\section{References}

1. Winn DM. Tobacco use and oral disease. J Dent Educ 2001;65:306-12.

2. Ko YC, Huang YL, Lee CH, Chen MJ, Lin LM, Tsai CC. Betel quid chewing, cigarette smoking and alcohol consumption related to oral cancer in Taiwan. J Oral Pathol Med 1995; 24:450-3.

3. Axell T, Holmstrup P, Kramer IR, Pindborg JJ, Shear M. International seminar on oral leukoplakia and associated lesions related to tobacco habits. Commun Dent Oral Epidemiol 1978; 46:518-39.

4. Kramer IR, Pindborg JJ, Bezroukov V, Infirri JS. Guide to epidemiology and diagnosis of oral mucosal diseases and conditions. World Health Organization. Commun Dent Oral Epidemiol 1980; 8:1-26.

5. Bhowate RR, Rao SP, Hariharan KK, Chinchkhede DH, Bharambe MS. Oral mucosal lesions among tobacco chewers: A community based study. Preventive section in XVI International Cancer Congress, Abstract Book-1, New Delhi: Allied Publishers Limited; 1994.

6. Maher R, Lee AJ, Warnakulasuriya KA, Lewis JA, Johnson NW. Role of areca nut in the causation of oral submucous fibrosis: A case-control study in Pakistan. J Oral Pathol Med 1994; 23:65-9.

7. Kramer IR, Lucas RB, Pindborg JJ, Sobin LH. Definition of leukoplakia and related lesions: An aid to studies on oral precancer. Oral Surg Oral Med Oral Pathol 1978; 46:518-39.

8. Aruna DS, Prasad KV, Shavi GR. Retrospective study on risk habits among oral cancer patients in Karnataka Cancer Therapy and Research Institute, Hubli, India. Asian Pacific J Cancer Prev 2011; 12:1561-6.

9. Reichart PA, Mohr U, Srisuwan S, Geerlings H, Theetranont C, Kangwanpong T.Precancerous and other oral mucosal lesions related to chewing, smoking and drinking habits in Thailand. Commun Dent Oral Epidemiol 1987; 15:152-60.

10. Zain RB, Razak IA: Association between cigarette smoking and prevalence of oral mucosal lesions among Malaysian army personnel. Community Dent Oral Epidemiol 1989; 17: 148-9.

How to cite this Article: Preeti Gupta1, Vivek Kumar Sharma², Karnika Yadav³ Pramod Kumar Yadav4*, Prateek Jain ${ }^{5}$, Ravinder Singh ${ }^{6}$ : Assessment of Tobacco Related Oral Practices Among Young Adult Workers Involved in Building Construction of Noida Area, India- A Cross-Sectional Survey

Int. J. Drug Res. Dental Sci., 2020; 2(1):1-4.



Source of Support: Nil, Conflict of Interest: None declared.

Received: 15-1-2020 Revised: 6-2-2020 Accepted: 10-2-2020 